\title{
Shunt compensator used for power quality improvement
}

\author{
Vipin kumar shukla ${ }^{1}$, Sudhanshu tripathi ${ }^{2}$ \\ M.Tech Scholar ${ }^{1}$, Assistant Professor ${ }^{2}$, Department of Electrical and Electronics Engineering \\ Sam Higginbottom Institute of Agriculture, Technology and Sciences, Allahabad, India
}

\begin{abstract}
This paper presents shunt compensator device to improve power quality which reduces the harmonic distortion and improves current maintaining the voltage unchanged. For this the shunt active power filter is used with the implementation of PI controller. In order to improve current, opposite harmonics are injected through the shunt active power filter and further it compared with the source current. This results improved power quality. Simulation results are presented to show that the power quality improvement using shunt active power filter.
\end{abstract}

Keywords: Active Power Filter, Power Quality, PI Controller

\section{Introduction}

The proliferation of microelectronics processors in a wide range of equipment's, from home VCRs and digital clocks to automated industrial assembly lines and hospital diagnostics systems, has increased the vulnerability of such equipment to power quality problems. These problems include a variety of electrical disturbances, which may originate in several ways and have different effects on various kinds of sensitive loads. What were once considered minor variations in power, usually unnoticed in the operation of conventional equipment, may now bring whole factories to standstill. As a result of this vulnerability, increasing numbers of industrial and commercial facilities are trying to protect themselves by investing in more sophisticate equipment to improve power quality. Moreover, the proliferation of nonlinear loads with large rated power has increased the contamination level in voltages and currents waveforms, forcing to improve the compensation characteristics required to satisfy more stringent harmonics standard. Between the different technical options available to improve power quality, active power filters have proved to be an important alternative to compensate for current and voltage disturbances in power distribution systems. Different active power filters topologies have been presented in the technical literature and many of them are already available in the market. This paper will focus in the analysis of which to use with their compensation characteristics. Shunt active power filters schemes will be presented and analysed. The control scheme characteristics for shunt schemes will also be discussed. Finally, steady state and transient results for dynamic compensation, obtained from simulated and experimental setup will be presented.

\section{Basic Configuration Of Active Power Filter}

Shunt active power filter compensate current harmonics by injecting equal-but-opposite harmonic compensating current. In this case the shunt active power filter operates as a current source injecting the harmonic components generated by the load but phase shifted by 180 o. This principle is applicable to any type of load considered a harmonic source. Moreover, with an appropriate control scheme, the active power filter can also compensate the load power factor. In this way, the power distribution system sees the nonlinear load and the active power filter as an ideal resistor. The current compensation characteristic of the shunt active power filter is shown in fig.

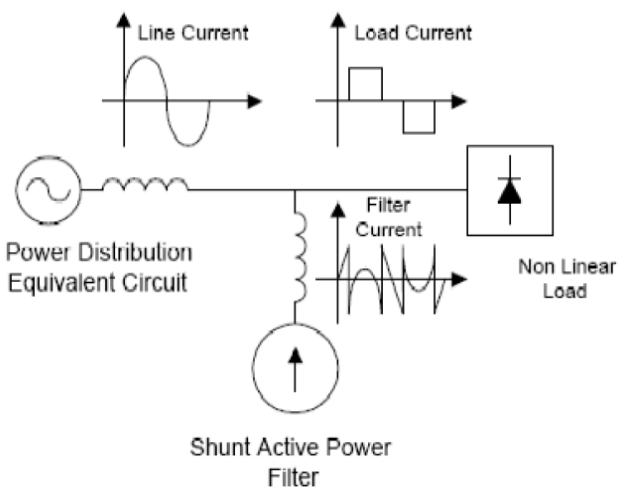

Fig. (1) Basic shunt active power filter 


\section{Principle Of Shunt Active Power Filter}

Harmonics contamination is a serious and a harmful problem in Electric Power System. Active Power filtering constitutes one of the most effective proposed solutions. A shunt active power filter that achieves low current total harmonic distortion (THD), reactive power compensation and power factor correction is presented. Hence, it is necessary to reduce the dominant harmonics below 5\% Harmonic Amplification is one the most serious problem. It is caused by harmonic resonance between line inductance and power factor correction capacitors installed by consumers. Active filters for damping out harmonic resonance in industrial and utility power distribution systems have been researched. Traditionally based, passive L-C filters were used to eliminate line harmonics. However, the passive filters have the demerits of fixed compensation, bulkiness and occurrence of resonance with other elements. The recent advances in power semiconductor devices have resulted in the development of Active Power Filters for harmonic suppression. Various topologies of active filters have been proposed for harmonic mitigation. The shunt APF based on Voltage Source Inverter (VSI) structure is an attractive solution to harmonic current problems. The SAF is a pulse width modulated (PWM) VSI that is connected in parallel with the load. It has the capability to inject harmonic current into the AC system with the same amplitude but opposite phase than that of the load. The principal components of the APF are the VSI, a DC energy storage device that in this case is capacitor, a coupling transformer and the associated control circuits. The performance of an active filter depends mainly on the technique used to compute the reference current and the control method used to inject the desired compensation current into the line.

\section{Control Techniques:}

\section{Modelling And Control Description}

There are several methods used to determinate the harmonic current references. In this study, we apply two methods, the notch filter and the synchronous reference theory

\section{A. Notch Filter Method:}

In this type of control the load current is filtered by a cut band filter which is sometimes called filter "notch". These cut band filters eliminate the fundamental component while letting the harmonic components. They therefore, the same cut frequency. In our study we have found that we can use a simple cut band filter but it does not have good insulation property. For that reason we have applied the method of notch filter which consists of two identical band pass filters in series, as shown in figure.

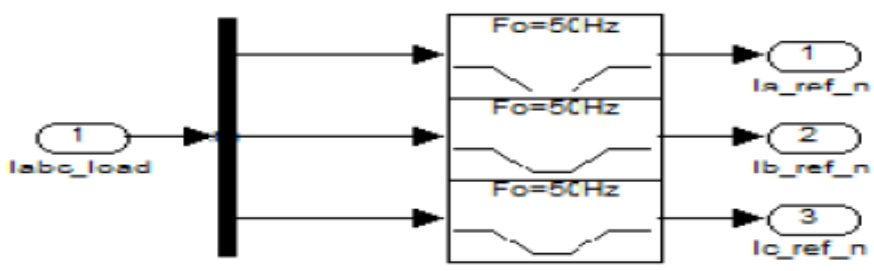

Fig (2) The band pass filter algorithm

\section{B. Synchronous Reference Method:}

This method involves transforming the coordinated a b-c of the current in coordinated $\mathrm{d}-\mathrm{q}$ and the assistance of the transforms of Park by setting the frequency thereof in synchrony with the network.

$$
\left[\begin{array}{l}
i d \\
i g
\end{array}\right]=2 / 3\left[\begin{array}{cc}
\sin (w t) \sin \left(w t-\frac{2 \pi}{3}\right) & \sin (w t+2 \pi / 3) \\
\cos (w t) \cos (w t-2 \pi / 3) & \cos \left(w t+\frac{2 \pi}{3}\right)
\end{array}\right]\left[\begin{array}{l}
i a \\
i b \\
i c
\end{array}\right]
$$

The park transformation transforms the fundamental current component to continuous component while the harmonic current components undergo a shift in the frequency spectrum, the continuous component can be eliminated by adding a high pass filter (HPF). Harmonic currents references can be obtained by performing the inverse transform of parks synchronized with network frequency as shown in figure. 3

$$
\left[\begin{array}{l}
i a * \\
i b * \\
i c *
\end{array}\right]=\left[\begin{array}{cc}
\sin (w t) & \cos (w t) \\
\sin (w t-2 \pi / 3) & \cos (w t-2 \pi / 3) \\
\sin (w t+2 \pi / 3) & \cos \left(w t+\frac{2 \pi}{3}\right)
\end{array}\right]\left[\begin{array}{l}
i d \\
i q
\end{array}\right]
$$




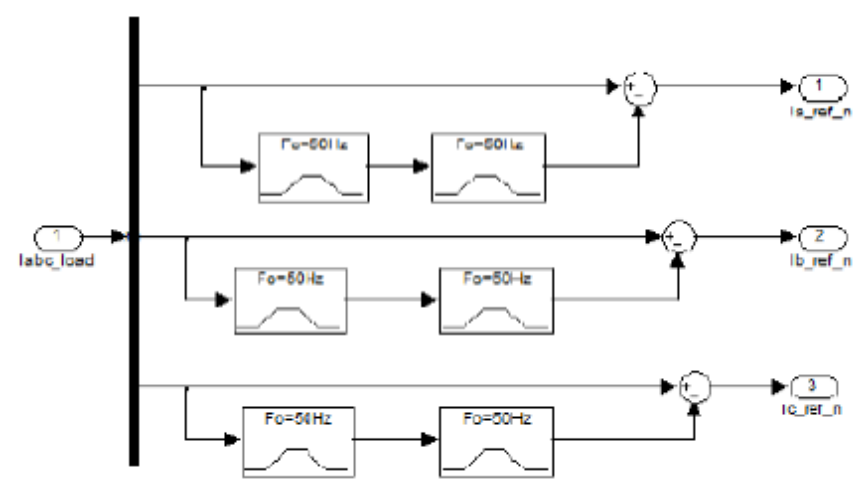

Fig. (3)Synchronous reference algorithm

Where:

$$
T f=\frac{K \cdot B \cdot F}{P 2+B \cdot P+W C 2}
$$

$\mathrm{K}$ is the gain, $\mathrm{P}$ is Laplace operator, $\mathrm{B}$ is an angular frequency equal to $2 \pi f \mathbf{b}, f \mathbf{b}$ is the width of the busy band and $\omega \mathbf{c}$ is the cut off frequency

\section{De Voltage Control:}

There are several current control strategies proposed in the literature, namely, PI control, Average Current Mode Control, Sliding Mode Control and hysteresis control. Among the various current control techniques, hysteresis control is the most popular one for active power filter applications. Hysteresis current control is a method of controlling a voltage source inverter so that the output current is generated which follows a reference current waveform in this project. Generally, PI controller is used to control the DC bus voltage of SAF. The PI controller based approach requires precise linear mathematical model. This project basically deals with the modelling and design of shunt active power filter for compensation of harmonics and reactive power. Designs of different parameters like power circuit, control circuit, control strategies, EMI/ Ripple factor are discussed shunt active power filter is controlled to draw or supply a compensating current. This compensating current injected by the active filter makes the supply current sinusoidal. In this manner, a shunt active filter can be used to eliminate the current harmonics in the system.

\section{PI Controller}

The figure 4 shows the PI control Scheme used in this paper, when the DC capacitor voltage Vc is sensed and compared with the reference value $\mathrm{Vc}^{*}$.*. The input of PI controller is the value of error, $\mathrm{e}=\mathrm{Vc} \mathrm{c}^{*}$ $\mathrm{Vc}$, and its output after a limit is considered as the magnitude of peak reference current Imax. The coefficients of PI controller, KP and KI, are fixed in our model to give a good performance dynamic for this active power filter

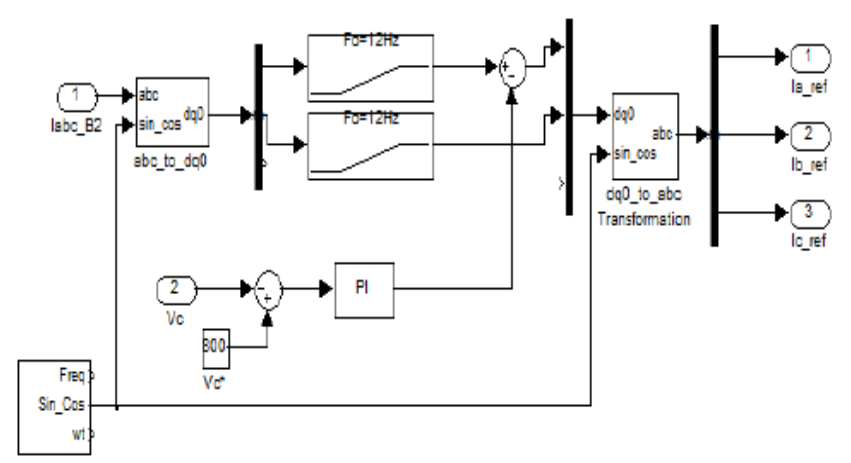

Fig (4) de voltage control using PI controller

\section{E. Current Control}

In this paper we have used the hysterisis current control; it's very commonly used because of its simplicity of implementation and it's rugged. This strategy provides satisfactory control of current without requiring extensive knowledge of control system model or its parameters. Figure 3.15 presents the principle of 
command that this is mainly to maintain each of the currents generated by the APF's in a band surrounding the reference currents.

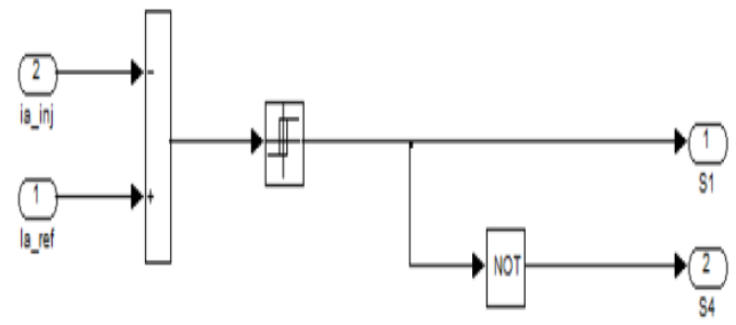

Fig. (5) Hysterisis current controller

Each violation of this band gives an order of commutation as the figure. 4 shows

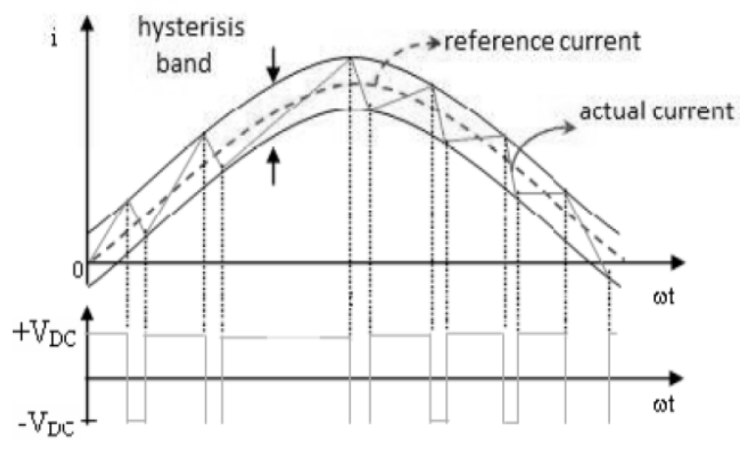

Fig (6) Hysterisis band curve

\section{Simulation Result And Discussion}

In this paper the simulation results are shown for the two conditions such as:

(a) Performance of system without using shunt active power filter

(b) Performance of system with shunt active power filter

(a) Without shunt APF

Model and simulation result for a without use shunt active power filter, shown in the figure.

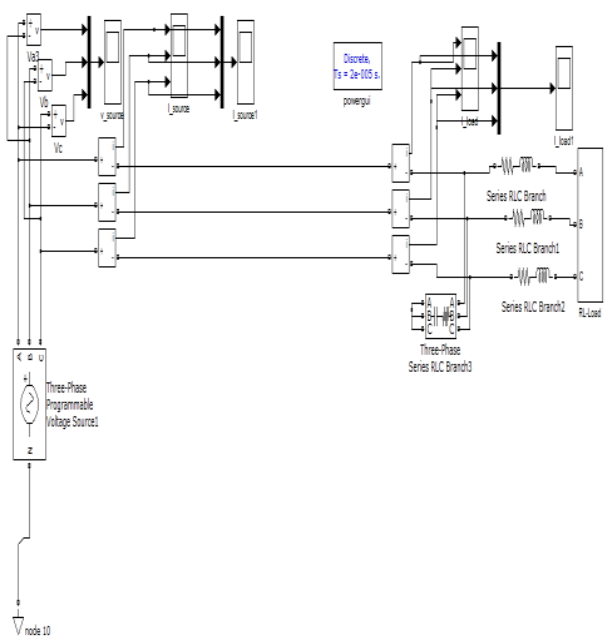

Fig. (7) Simulink Model without shunt APF 


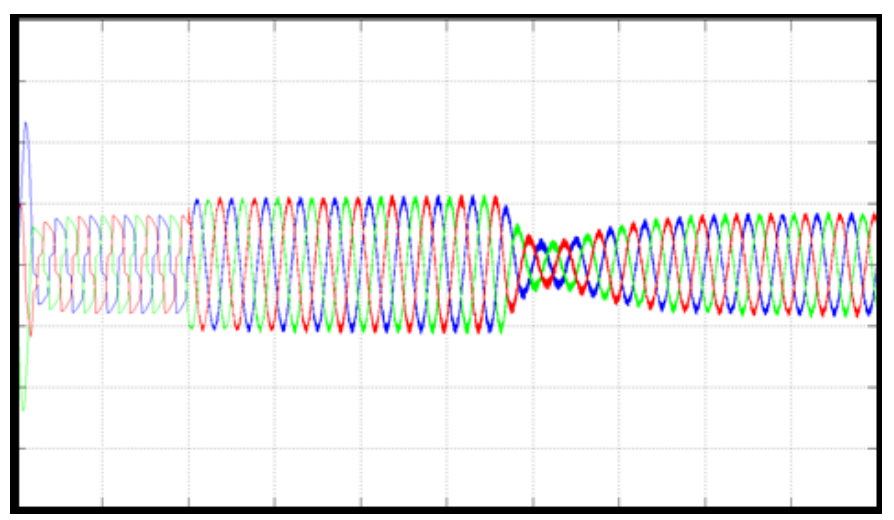

Fig.(8) Waveform without shunt APF

(b) Use shunt active power filter

Model and simulation result for a with shunt active power filter are shown in the figure.

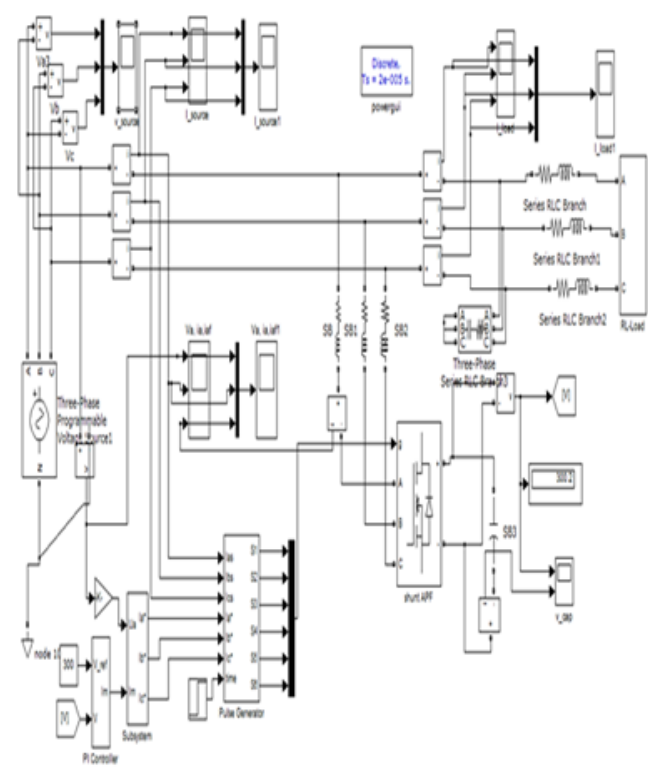

Fig. (9) Simulink Model with shunt APF

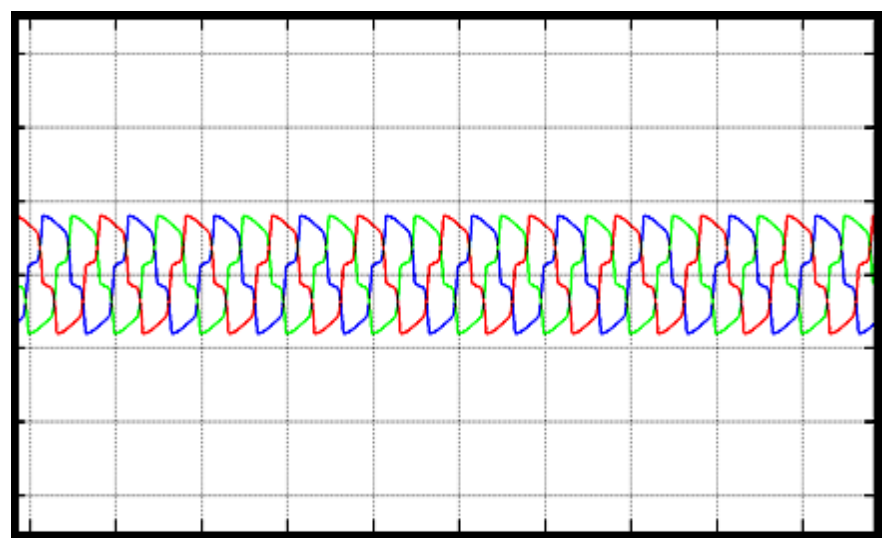

Fig. (10) Waveform with shunt APF 


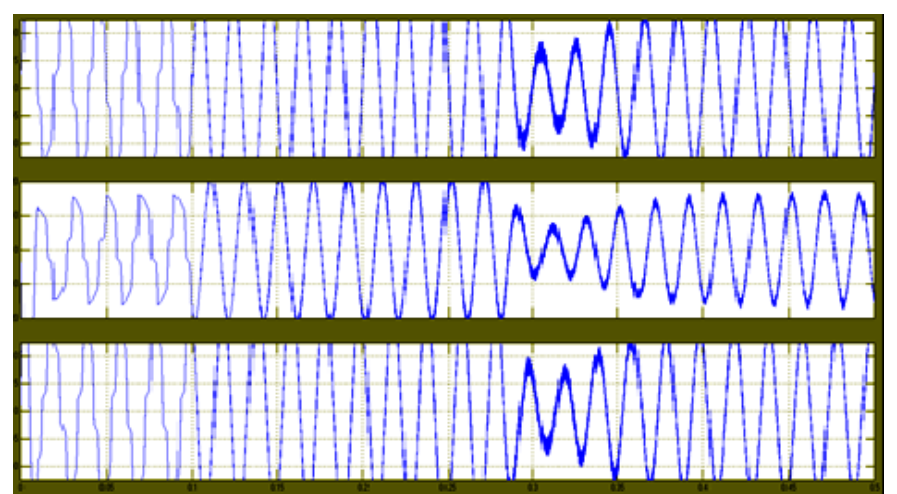

Fig. (11) Source current before and after compensation

The waveform shown in fig. 11 demonstrates that source voltage, source current before and after compensation and filter current for phase A.

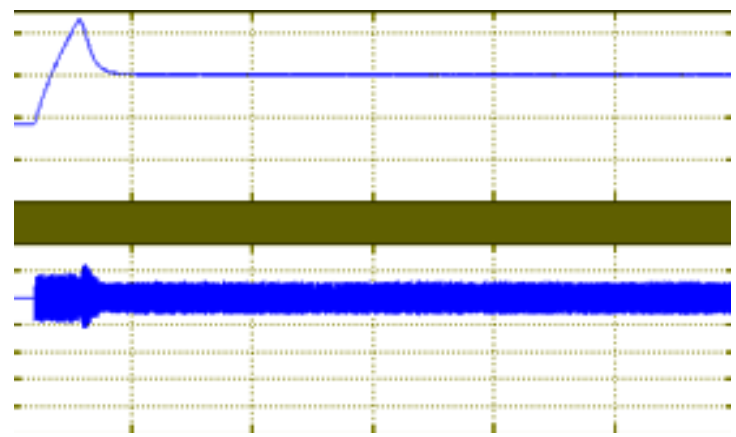

Fig (12) capacitor voltage and capacitor current

The waveform shown in fig. 12 demonstrates that capacitor voltage settles at nearly constant value of Vdc ref. and capacitor current settles at almost equal to the value of filter current

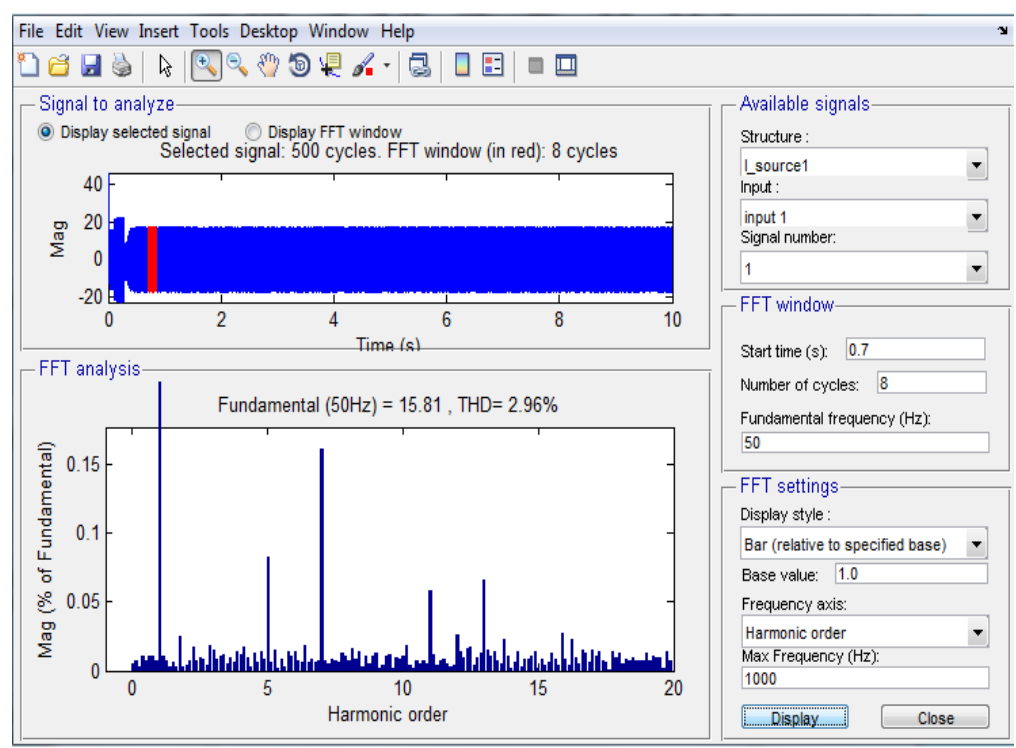

Fig. (13) FFT analysis for load current

The performance of the system improves and the THD is reduced up to very large extent. Also, it is seen from the simulation results that the source current and the source voltages are in same phase i.e. the input power factor is unity and there is no reactive power from the source. 


\section{Conclusion}

In this paper we have studied the shunt active power filter with PI controller for power quality improvement .The power quality problems, circuit topology and operating principle of proposed shunt compensator are analysed in detail and some of the power quality problems which can be solved by shunt compensator are also discussed in the paper. Finally a Matlab/Simulink based model is developed and simulation results are present.

It was also observed that the location where the Shunt active power filter is connected in the electrical system which is very important for improvement of overall system dynamics performance. Shunt active power filter compensator will become a good solution for power quality improvement

\section{References}

[1] H. Akagi, Y. Kanazawa, A. Nabae, Generalized Theory of the Instantaneous Reactive Power in Three-Phase Circuits, IPEC'83 - Int. Power Electronics C-onf., Tokyo, Japan, 1983, pp. 1375-1386.

[2] H. Akagi, Y. Kanazawa, A. Nabae, Instanataneous Reactive Power Compensator Comprising Switching Devices without Energy Storage Compenents", IEEE Trans. Industry Applic., vol. 20, May/June 1984

[3] E. H. Watanabe, R. M. Stephan, M. Aredes, New Concepts of Instantaneous Active and Reactive Powers in Electrical Systems with Generic Loads, IEEE Trans. Power Delivery, vol. 8, no. 2, April 1993, pp. 697, 703

[4] M. Aredes, E. H. Watanabe, New Control Algorithms for Series and Shunt Three-Phase Four-Wire Active Power Filters, IEEE Trans. Power Delivery, vol 10, no. 3, July 1995, pp. 1649-165

[5] ARRILAGA, J., BRADLEY, D.A., and BODGER, P.S.: 'Power system harmonics' (John Wiley and Sons, 1985)

[6] VAN WYK. J.D.: 'Power aualitv, power electronics and control'. Pro- ceedings of European Powe; 'Electronics conference, EPE93, Brighton, UK, September 1993, pp. 17-32

[7] HAYASHI, Y., SATO, N., and TAKAHASHI, K.: 'A novel control of a current source active filter for ac power system harmonic compensation', IEEE Trms., 1991, IA-27, (2), pp.380-384

[8] FUKUDA, S., and YAMAJ, M.: 'Design and characteristics of active power filter using current source converter'. IEEE Industrial Application Society annual meeting, 1990, pp. 965-970

[9] George M, K. P. Basu, Three-Phase Shunt Active Power Filter, American Journal of Applied Sciences, vol. 1, 2008 , pp. 909-916. 1020

[10] Hafner J, M. Aredes, K. Heumann, A Shunt Active Power Filter Applied to High Voltage Distribution Lines, IEEE Trans. on Power Delivery, vol. 12, no. 1, 1997, pp. 266- 272.

[11] Dixon W, J. J. Garcia. and L. Moran, Control System for Three-Phase Active Power Filter which Simultaneously Compensates Power Factor and Unbalanced Loads, IEEE Transaction on Industrial Electronics, vol. 42, no. 6, 1995, pp. 636-641

[12] Bhattacharya S, D. M. Divan, E. E. Banerjee, Control and Reduction of Terminal Voltage Total Harmonic Distortion (THD) in a Hybrid Series Active and Parallel Passive Filter System, in Proc. IEEE-PESC'93-PowernElectronics Spec. Conf., 1993, pp. 779-786.

[13] Singh B, K. Al-Haddad. and A. Chandra, A New Control Approach to Three-Phase Active Filter for Harmonics and Reactive Power Compensation, IEEE Transactions on Power Systems, vol. 13, no. 1, 1998, pp. 133-136

[14] M. H. Rashid, Power Electronics: Circuits, Devices, and Applications, 3rd ed. Englewood Cliffs, NJ: Prentice-Hall, 2004, p. 267

[15] Steeper D. E. and R. P. Stratford, Reactive compensation and harmonic suppression for industrial power systems using thyristor converters, IEEE Trans. Ind. Appl., vol. 12 no. 3, 1976,pp.232-254. 